\title{
A Qualitative Analysis of Stay-At-Home Parents' Spanking Tweets
}

\author{
Joyce Y. Lee $\mathbb{D}^{1,2} \cdot$ Andrew C. Grogan-Kaylor ${ }^{1} \cdot$ Shawna J. Lee ${ }^{1} \cdot$ Tawfiq Ammari $^{3} \cdot$ Alex Lu $^{1,3} \cdot$ Pamela Davis-Kean $^{2}$
}

Published online: 9 January 2020

(c) Springer Science+Business Media, LLC, part of Springer Nature 2020

\begin{abstract}
Objective This qualitative study used Twitter to examine stay-at-home parents' publicly available postings to Twitter about discipline and spanking. Many adults still support the use of spanking despite a substantial body of evidence demonstrating that spanking is linked to a range of negative child outcomes. Little is currently known about how parents think about spanking as a disciplinary practice and how parents express these beliefs online.

Method Five million publicly available tweets were collected from self-identified stay-at-home parents. Tweets were screened for discipline and spanking content. A qualitative analysis was conducted on the final set of tweets $(N=648)$.

Results Stay-at-home parents were most likely to tweet about information related to discipline and spanking compared to tweets that made up other global themes (e.g., discipline tips). Parents most commonly posted tweets that reflected their antispanking beliefs compared to tweets that made up other subthemes (e.g., pro-spanking). Tweets in support of spanking emerged as well, with fathers being more likely than mothers to tweet about pro-spanking beliefs and desires. However, mothers were more likely than fathers to tweet about pro-spanking behaviors.

Conclusion Our results provide evidence that stay-at-home parents turn to Twitter to obtain disciplinary information and disclose their anti-spanking and pro-spanking beliefs. Anti-spanking tweets potentially reflect changing social norms and suggest that some stay-at-home parents on Twitter may be engaging in selective self-presentation. Thus, Twitter may be one avenue to use for interventions to set social norms that aim to reduce parental corporal punishment.
\end{abstract}

Keywords Discipline $\cdot$ Corporal punishment $\cdot$ Spanking $\cdot$ Twitter $\cdot$ Stay-at-home parents $\cdot$ Social media

Parents are a group who frequently use social media networks. A Pew Research Center survey found that threequarters of parents use social media, with mothers generally being more likely than fathers to use social media (Duggan et al. 2015). This is consistent with research on new parents' use of Facebook, showing that mothers were more likely to use Facebook than fathers during their transition to parenthood (Bartholomew et al. 2012). Parents use social media for several reasons, including obtaining social support, asking parenting questions to their social networks,

Joyce Y. Lee

joyceyl@umich.edu

1 School of Social Work, University of Michigan, 1080 S. University Ave., Ann Arbor, MI 48109, USA

2 Department of Psychology, University of Michigan, Ann Arbor, MI 48109, USA

3 School of Information, University of Michigan, Ann Arbor, MI 48109, USA and acquiring parenting information (Duggan et al. 2015; Lee and Lee 2018). Further, parents have identified social media as a source of useful information and parenting tool, with mothers using it as a parenting resource-both for information and social support-more often than do fathers (Duggan et al. 2015).

Studies examining anonymous or pseudonymous social media platforms have found that such outlets could potentially serve as places for parents to discuss sensitive parenting topics (Ammari et al. 2018; Schoenebeck 2013). In an analysis of 51 million posts and comments from an anonymous message board for mothers (i.e., YouBeMom. com), Schoenebeck (2013) found that mothers most commonly referenced their husbands and were likely to express their negative emotions towards them. Analyzing approximately 1.5 million comments from Reddit, a pseudonymous discussion website, Ammari et al. (2018) found that parents commonly discussed discipline, vaccinations, child custody, and circumcision-topics that are typically considered divisive and thus avoided on Facebook (Ammari and Schoenebeck 2015). These findings suggest that parents 
may turn to social media platforms where anonymity or pseudonymity are ensured when wishing to discuss sensitive parenting issues. However, less is known about how parents behave on less anonymous social media platforms, such as Twitter.

Approximately $23 \%$ of parents ages 18-65 use Twitter, with no significant difference between mothers and fathers (Duggan et al. 2015). Twitter allows users to broadcast their thoughts and opinions to a wider network of followers compared to Facebook (Bazarova and Choi 2014). This is because Twitter does not require that a user request to become a "friend" before being included in one's social network. Rather, a user simply clicks the "follow" button on another user's profile to become a follower irrespective of online friendship. Further, Twitter gives users the option to self-disclose their thoughts either using pseudonyms or users' real names (van der Nagel 2018).

Goffman (1959) first developed the theory of self-presentation, which posits that actors on stage (in this case, social media platforms) use various verbal and nonverbal cues, as well as adapt what they say, change their tone of voice, and switch what they wear to achieve the preferred impression from their audience. Those who engage in selfrepresentation do so for identity maintenance, economic or social gains, and self-esteem (Goffman 1959). Selfpresentation theory also notes that the audience the actor or individual is interacting with is simultaneously trying to form opinions or obtain information about that person. As a result, all those participating in the social encounter will engage in certain set of behaviors to avoid embarrassment of themselves (Goffman 1959). Prior research suggests that Twitter users use profiles and tweets as their "stage" to perform for their followers (Brems et al. 2017; Cha et al. 2010). By tweeting, censoring their tweets, and managing their retweets, Twitter users proactively control how their followers perceive them (Uski and Lampinen 2016; Vitak 2012). This process of curating one's self-image is an ongoing process on Twitter (Brems et al. 2017), with a focus on maintaining positive impressions while also appearing authentic to followers (Marwick and Boyd 2011). The self-presentation literature suggests that Twitter users may deliberately present themselves in a positive manner, especially when discussing controversial topics (i.e., corporal punishment).

Corporal punishment is defined as "the use of physical force with the intention of causing a child to experience pain, but not injury, for the purpose of correcting or controlling the child's behavior" (Donnelly and Straus 2005, p. 3). Corporal punishment is also commonly known as spanking, hitting, popping, or whooping (Brown et al. 2016; Fréchette and Romano 2017) and has been identified globally to be the most common form of violence against children (United Nations Children's Fund 2014). Over the last several decades, much attention has been paid to the question of how corporal punishment affects children's mental and socio-behavioral health outcomes. That is, a substantial body of research, including a recent metaanalysis (Gershoff and Grogan-Kaylor 2016), suggests that spanking does not improve children's behavior and is linked with increases in child behavior problems.

Although research has repeatedly demonstrated the associations between spanking and undesired child outcomes, most adults in the United States support the use of corporal punishment (Child Trends 2015). Some evidence suggests that parents believe spanking actually improves child behaviors (Holden et al. 2014; Taylor et al. 2016). Taylor et al. (2016) analyzed online comments $(N=581)$ on media coverage of a corporal punishment study and found that approximately $70 \%$ of the comments expressed approval of spanking a child for discipline. Reasons for approving spanking were rooted in the beliefs that spanking is linked with positive or neutral outcomes, today's generation is worse than prior generations, one's religion guides disciplinary practices, and that children have too much power.

Research findings have been inconsistent about whether mothers and fathers differ in their use of corporal punishment. Some studies have found that mothers and fathers are more similar than different in their use of spanking (Holden et al. 1999; Wissow 2001). Other studies have shown that mothers use more spanking than fathers do (Kim et al. 2014; Lansford et al. 2010). One reason for this gender difference in parents' use of spanking may be because mothers typically spend more time with their children and engage in more daily caregiving activities compared to fathers (Day and Lamb 2004). Mothers may be more exposed than fathers to their children's misbehaviors and thus have more opportunities to respond with disciplinary actions such as spanking (Lansford et al. 2010).

There are other differences in how mothers and fathers parent their children, although some argue that such differences are not very large, and there are likely to be a number of underlying similarities between mothers and fathers (Jeynes 2016). For instance, fathers are less likely than mothers to report self-efficacy related to infant care (Hudson et al. 2001), engage in caregiving activities and house chores (Pelchant et al. 2003), and seek out parenting information from online blogs (Fraga 2017). Less is known about the parenting behaviors of non-traditional parents, such as stay-at-home fathers who have been described as those defying traditional norms about the division of labor and gender by being primary caregivers of their children and proactively engaging in nurturing behaviors (Solomon 2014). Nevertheless, stay-at-home fathers still hold some views-such as the need to be independent, not ask for help, and feel respected by others-that may be interpreted as adhering to traditional gender norms (Lee and Lee 2018). 
The current study was exploratory in nature with the aim to isolate a group of self-identified parents (i.e., stay-athome parents) and examine their publicly available tweets concerning discipline and spanking. In particular, the study employed self-presentation theory to explore the specific ways in which stay-at-home mothers and stay-at-home fathers talk about spanking as a disciplinary method. Based on the theory, we speculated that some stay-at-home parent Twitter users might deliberately present themselves in a positive manner when discussing the topics of child discipline and spanking. Wanting to be viewed favorably by their followers and larger networks and thus hedging or even hiding true opinions about spanking may have important implications for determining the accuracy of parents' opinions of spanking expressed on Twitter, as well as development of social media-based interventions. The current study makes an important contribution to the literature by using observational data publicly available on a virtual setting and utilizing the self-presentation theory as its main theoretical framework to critically assess and interpret parents' behaviors on social media.

\section{Method}

\section{Participants}

\section{Twitter users}

Participants were stay-at-home parents who were also Twitter users. We were interested in both stay-at-home mothers and stay-at-home fathers. That said, stay-at-home fathers (and fathers in general), represent a group that is challenging to reach through traditional means of recruitment (Stahlschmidt et al. 2013). As such, research with fathers has suggested that snowball sampling, a technique where the next set of study subjects are gathered from the acquaintances of the current study subjects, may be an effective way to recruit fathers (Stahlschmidt et al. 2013). The current study was part of a larger big data project that involved research questions related to exploring parenting topics that stay-at-home parents discuss as a group on Twitter, which required that we identify and track stay-athome parents' followers, who were also stay-at-homeparents themselves. Given the larger study's aim and our interest in stay-at-home fathers (and mothers), we deemed snowball sampling to be an appropriate sampling method.

\section{Procedure}

Data on individual tweets were collected from Twitter. Tweets are publicly available data that are typically 140 characters or less, although the character limit has recently increased to 280 (Tsukayama 2017). Twitter is a public forum in which users follow real-time information and can network with other users by following the feed of other user accounts (Lyles et al. 2013). Despite the limited number of characters allowed in each tweet, tweets are often rich in content since links to news articles, blogs, pictures, videos - as well as information on other user accounts and conversations between users-can be detected (Lyles et al. 2013). Individual Twitter accounts can either be public or private depending on the user's preference.

First, we used Twitter's publicly available Streaming API across a time period of 30 days, from April 24, 2017, to May 23, 2017, to query hashtags using the following terms for stay-at-home parents: \#stayathomedad, \#stayathomemom, \#stayathomefather, \#stayathomemother, \#sahd, \#sahf, and \#sahm. This yielded a dataset of 9665 Twitter users who mentioned one or more of these hashtags in their tweets. After excluding duplicates, we were left with 3087 unique Twitter users. We then employed regular expressions, a sequence of characters and symbols expressing a pattern to be searched for within texts, to the users' profiles to obtain the first set of self-identifying stay-at-home mothers $(n=37)$ and stay-at-home fathers $(n=15)$. This first set served as the seed dataset from which to build the next set of stay-at-home parents. Self-identifying stay-athome parent users were defined as those who explicitly described themselves as a stay-at-home mother or stay-athome father in their individual Twitter profiles (e.g., "Stay at home dad with 2 beautiful girls and letting the world watch through my blog," and "I am a chubby jolly stay at home wife and mom").

In accordance with the snowball sampling method, we first obtained the handles of those following stay-at-home parents in the seed dataset. We used Twitter's publicly available Resting API, which allowed us to request 3000 followers every 15 min (Twitter, Inc. n.d.a). Our attempt to obtain the first iteration of followers yielded a total of 72,565 unique followers. Of these, 209 identified themselves as stay-at-home fathers, and 761 were identified as stay-at-home mothers based on content found in the users' Twitter profiles. We then used the handles of these stay-athome parents to obtain the next iteration of followers. The second iteration yielded a total of 812,183 unique followers. Of these, 9462 identified themselves as stay-at-home fathers and 35,130, as stay-at-home mothers in their Twitter profiles. Next, we combined the seed dataset, first iteration of followers, and second iteration followers and cleaned the larger dataset, excluding duplicate handles, dead accounts, and protected accounts. This process yielded 685 unique stay-at-home father handles and 4103 stay-at-home mother handles. The disproportionate number of handles between the genders led us to run another iteration of followers for stay-at-home fathers. The third iteration only yielded 12 
Fig. 1 Distribution of tweets with spanking synonyms by stay-at-home parent gender. The total number of tweets include double-coded tweets: $n=69$ stay-at-home father spanking tweets; $n=240$ stayat-home mother spanking tweets

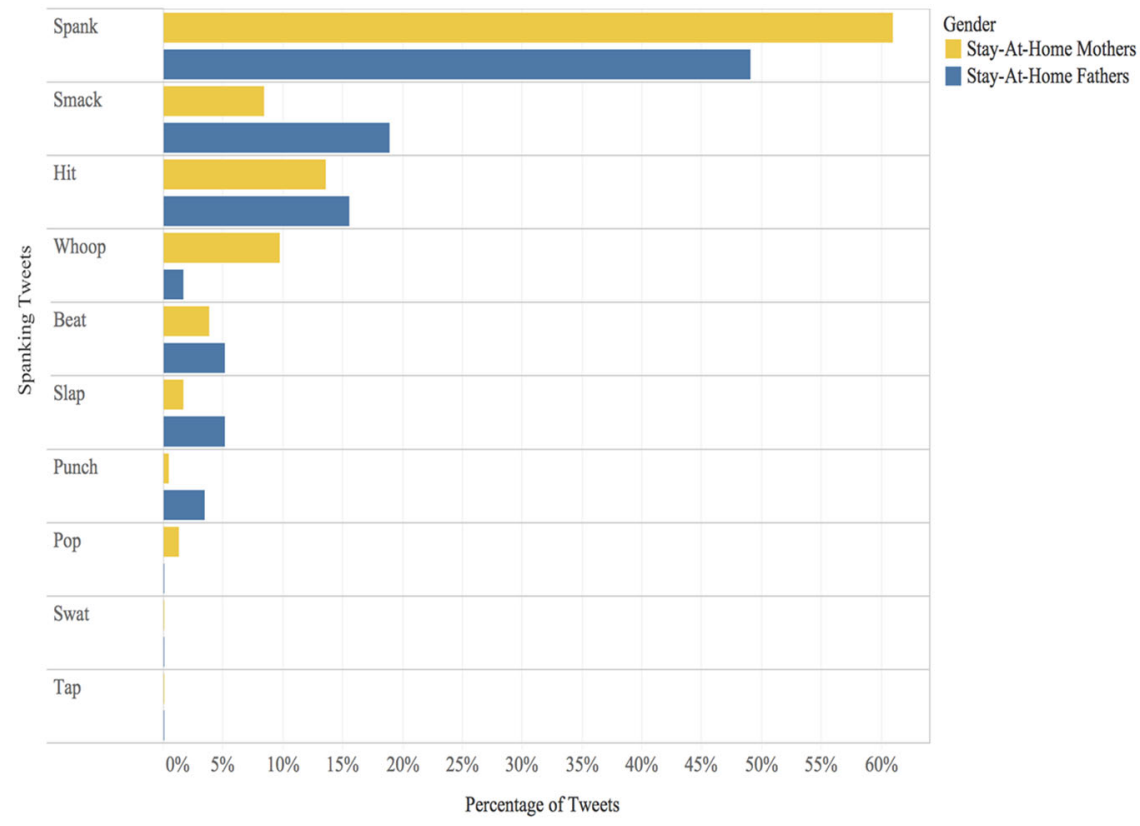

new handles, suggesting diminishing returns. The final dataset included 697 unique stay-at-home father handles and 4103 unique stay-at-home mother handles.

We used Twitter's publicly available Resting API and the final dataset to obtain stay-at-home parents' tweets. Twitter returns up to 3200 of the most recent tweets for each user (Twitter, Inc. n.d.b). We obtained a total of 5,631,109 stay-athome parents' tweets in a few weeks. Specifically, 936,985 tweets were from the 697 stay-at-home father users, and 4,694,124 tweets were from the 4103 stay-at-home mother users in the final dataset. Hereinafter, stay-at-home fathers are simply referred to as fathers and stay-at-home mothers as mothers.

\section{Discipline and spanking tweets}

Given our interest in stay-at-home parents' tweets related to discipline and spanking, we used regular expressions to identify tweets with the stemmed versions of the words discipline and spank in them. Using this method, we identified all related variations (e.g., disciplined, disciplinarian, spanker, spanking). We screened identified tweets for discipline and spanking tweets in the context of parenting. That is, we eliminated tweets that may have used the words discipline and spank (and their variations) but occurred in or referenced contexts other than parental discipline (e.g., selfdiscipline: "I need to discipline myself to go to the gym more often. A disciplined life is a happy life. \#MondayMotivation"; sports: "The Eagles totally spanked Patriot's butt! \#GoEagles \#NFL). A total of 282 fathers' tweets mentioned the word discipline or any of its variations, and of these tweets, 66 pertained to discipline in the context of parenting. A total of 119 fathers' tweets mentioned the word spank or any of its variations, and of these, only 28 pertained to spanking in the context of disciplining a child.

Given the small number of tweets that mention spanking, we decided to use synonyms of spanking to build a corpus of spanking tweets. We reviewed the corporal punishment terminology literature which has demonstrated that parents use terms, such as "beat," "punch," "slap," "tap," and "whoop" to refer to spanking (Brown et al. 2016; Fréchette and Romano 2017; Gershoff and Grogan-Kaylor 2016). Based on these efforts, we identified the following synonyms of spanking: smack, slap, whoop, beat, hit, punch, swat, pop, and tap. Once more, regular expressions were used to identify tweets containing the above synonyms, and each of these tweets was screened to assess for spanking in the context of parental discipline. For example, a total of 122 fathers' tweets mentioned the word smack or any of its variations, and of these tweets, 11 pertained to smacking in the context of disciplining a child. A detailed breakdown of the proportion of each tweeted synonym is provided in Fig. 1. Fathers' spanking corpus increased from 28 to 56 tweets. We employed the same method for mothers' discipline and spanking tweets. Mothers' spanking corpus increased from 144 to 211 tweets.

\section{Data Analyses}

Given the small number of fathers' and mothers' tweets, we decided to conduct qualitative analysis to examine themes that emerged from stay-at-home parents' tweets. Consistent with prior studies that qualitatively examine tweets (Lyles et al. 2013), we first examined $20 \%$ of stay-at-home 
parents' discipline and spanking tweets (including all synonyms). Hereafter, spanking tweets refer to the corpus we created by merging all spanking and spanking synonym tweets. From $20 \%$ of the tweets, we developed an overall coding scheme that included five global themes for both discipline tweets and spanking tweets. Subsequently, we developed a codebook that listed each global code, along with descriptions of the code, instructions for using the code, and example tweets related to the code.

The first author trained coders to use the codebook appropriately, and two masters-level coders coded the remaining tweets. Coded results were compiled on a Google Sheet. The coders wrote memos while coding as a way to provide a rationale for each code. They engaged in additional exchange of memos during meetings where coded results were compared and discrepancies in coding were discussed. Where the coders could not resolve disagreement, a third member of the research team intervened to help the coders reach a consensus. Several tweets were ambiguous in their meanings. Hence, we searched for the actual tweets on Twitter to examine the context of the tweets (e.g., conversations with other users). Retweetstweets forwarded from another source to one's own followers-were interpreted as expressing agreement with the original tweets, if not endorsement. This was determined based on research showing that retweeting is likely to indicate agreement with the content of a tweet or endorsement of its message (Metaxas and TwitterTrails Research Team 2017). All co-authors checked the coded results for accuracy in coding and agreement between the two coders.

Given our primary interest in stay-at-home parents' corporal punishment tweets, we further coded spanking tweets for subthemes. This sub-coding process was iterative. The first author developed a preliminary set of subcodes and incorporated them into the codebook. Then, the first author and a research assistant independently applied the subcodes to small proportions of the spanking tweets (20\%). Next, the pair met to compare their coded results and engage in discussion to further refine the subcodes (e.g., by collapsing or eliminating subthemes). Regular exchange of memos took place during this process, as well as consulting co-authors for their inputs. Several rounds of these meetings, discussions, and exchange of memos resulted in a full set of subthemes which were edited in the codebook accordingly. The final codebook was reviewed by all the coauthors for approval.

Using this finalized codebook, the same two masterslevel coders independently engaged in the coding of the remaining spanking tweets. To account for overlap in themes, tweets with more than one subtheme were allowed to be double-coded with other subthemes. The coders wrote extensive memos while coding the remaining spanking tweets as a way to provide rationale for each code. Coders engaged in additional exchange of memos at meetings where they compared results and resolved discrepancies in their coding. Further, the coders called upon a third member of the research team to help them reach consensus on coding disagreements. This third member also independently examined the two coders' double-coded results. Finally, all co-authors checked the final coded results for spanking tweets for accuracy and agreement. Although intercoder reliability can be helpful for ensuring consistency of coding, some researchers have argued that the numeric measures (e.g., Cohen's $\kappa)$ are easily influenced by many arbitrary factors (Milford et al. 2017). The Cohen's $\kappa$ for the current study was 0.90 , which is considered almost perfect agreement (McHugh 2012). However, Cohen's $\kappa$ is known to have a number of limitations including the potential to lower the estimate of agreement excessively and lack of direct interpretation. (McHugh 2012). As such, we relied heavily on the iterative method of meeting regularly, engaging in in-depth discussions, and taking extensive memos for establishing agreement between coders and for our overall decision-making process.

\section{Results}

A total of 648 tweets were coded altogether, with 122 tweets from fathers and 526 tweets from mothers. These tweets were generated by 43 fathers and 126 mothers. Of the 122 fathers' tweets, 66 were general discipline tweets, and 56 were spanking tweets. The total spanking tweets increased to 69 after accounting for double-coded tweets (i.e., 13 spanking tweets were double coded for fathers). The most commonly used synonyms for spanking in fathers' corpus of spanking tweets were smack and hit, and the least commonly used synonyms were pop, swat, and tap. Of the 526 mothers' tweets, 315 were general discipline tweets, and 211 were spanking tweets. The total spanking tweets increased to 240 after accounting for double-coded tweets (i.e., 29 spanking tweets were double coded for mothers). The most commonly used synonyms for spanking in mothers' corpus of spanking tweets were hit and whoop, and the least commonly used synonyms were pop, swat, and tap (see Fig. 1).

\section{Discipline Tweets}

Five identical global themes emerged from fathers' and mothers' discipline tweets: (1) discipline tips; (2) positive discipline; (3) personal beliefs about discipline; (4) experiences of disciplining a child; and (5) facts or information related to discipline. Discipline tip tweets offered parenting 
advice related to various forms of discipline. Positive discipline tweets included content related to non-violent forms of discipline (e.g., time-outs). Personal beliefs about discipline tweets reflected stay-at-home parents' beliefs related to different disciplinary practices. Facts or information tweets were concerned with information related to various forms of discipline.

Stay-at-home parents most commonly tweeted about facts or information related to discipline $(38.43 \%)$, followed by their personal beliefs about discipline $(20.83 \%)$, and experiences of disciplining a child $(20.37 \%)$. In general, the tweet content was similar across fathers and mothers. Fathers most commonly tweeted about their experiences of disciplining a child $(33.3 \%)$ and facts or information related to discipline $(31.8 \%)$. Mothers most frequently tweeted about facts or information related to discipline $(46.0 \%)$ and their personal beliefs about discipline (24.8\%). Discipline tips were the least frequently tweeted global themes for both genders. We did not code the discipline tweets for subthemes as our aim was to focus primarily on coding spanking tweets in detail.

\section{Spanking Tweets}

Five global themes also emerged from fathers' and mothers' spanking tweets. These included (1) anti-spanking; (2) prospanking; (3) unsure about spanking; (4) experiences related to spanking; and (5) facts or information related to spanking. Anti-spanking tweets included content suggestive of an anti-spanking stance. Similarly, pro-spanking tweets included content suggestive of a pro-spanking stance. Unsureabout-spanking tweets reflected conflict about using spanking. Experiences-related-to-spanking tweets dealt with experiences involving spanking. Facts or information tweets were primarily concerned with information related to spanking.

Stay-at-home parents most commonly tweeted about facts or information related to spanking (37.54\%), followed by an anti-spanking stance $(27.18 \%)$, and a pro-spanking stance $(22.01 \%)$. Both fathers and mothers posted antispanking tweets $(31.88 \%$ for fathers, $25.83 \%$ for mothers) and pro-spanking tweets $(24.64 \%$ for fathers, $21.25 \%$ for mothers). Both parent groups were slightly more likely to post tweets against spanking than tweets in favor of spanking. Fathers were slightly more likely than mothers to post tweets expressing their anti-spanking and pro-spanking stances. Fathers were also more likely than mothers to tweet about being unsure about spanking. In contrast, mothers were more likely than fathers to post tweets related to spanking information (for details, see Table 1). Results from further coding the global themes yielded several subthemes (Fig. 2 and Table 1). The following section delineates results from qualitatively analyzing subthemes.
Table 1 Global themes, subthemes, and frequencies of spanking tweets

\begin{tabular}{|c|c|c|c|c|c|c|}
\hline \multirow{2}{*}{$\begin{array}{l}\text { Global themes and } \\
\text { subthemes }\end{array}$} & \multicolumn{2}{|c|}{ Overall } & \multicolumn{2}{|c|}{ SAHFs } & \multicolumn{2}{|c|}{ SAHMs } \\
\hline & $n$ & $\%$ & $n$ & $\%$ & $n$ & $\%$ \\
\hline 1. Anti-spanking & 84 & 27.18 & 22 & 31.88 & 62 & 25.83 \\
\hline a. Anti-spank belief & 66 & 21.36 & 14 & 20.29 & 52 & 21.67 \\
\hline b. Anti-spank reflection & 12 & 3.88 & 7 & 10.14 & 5 & 2.08 \\
\hline c. Anti-spank behavior & 6 & 1.94 & 1 & 1.45 & 5 & 2.08 \\
\hline 2. Pro-spanking & 68 & 22.01 & 17 & 24.64 & 51 & 21.25 \\
\hline a. Pro-spank belief & 20 & 6.47 & 8 & 11.59 & 12 & 5.00 \\
\hline b. Pro-spank desire & 6 & 1.94 & 2 & 2.90 & 4 & 1.67 \\
\hline c. Pro-spank behavior & 35 & 11.33 & 5 & 7.25 & 30 & 12.50 \\
\hline d. Pro-spank others & 7 & 2.27 & 2 & 2.90 & 5 & 2.08 \\
\hline $\begin{array}{l}\text { 3. Experiences related to } \\
\text { spanking }\end{array}$ & 32 & 10.36 & 5 & 7.25 & 27 & 11.25 \\
\hline a. Spanked as child & 18 & 5.83 & 4 & 5.80 & 14 & 5.83 \\
\hline b. Discipline advice & 5 & 1.62 & 0 & 0.00 & 5 & 2.08 \\
\hline $\begin{array}{l}\text { c. Others' spanking } \\
\text { experience }\end{array}$ & 9 & 2.91 & 1 & 1.45 & 8 & 3.33 \\
\hline 4. Unsure about spanking & 9 & 2.91 & 4 & 5.80 & 5 & 2.08 \\
\hline $\begin{array}{l}\text { 5. Facts or information } \\
\text { related to spanking }\end{array}$ & 116 & 37.54 & 21 & 30.43 & 95 & 39.58 \\
\hline a. Informational & 55 & 17.80 & 11 & 15.94 & 44 & 18.33 \\
\hline b. Information-seeking & 29 & 9.39 & 7 & 10.14 & 22 & 9.17 \\
\hline c. Help-seeking & 4 & 1.29 & 0 & 0.00 & 4 & 1.67 \\
\hline d. Blog post & 28 & 9.06 & 3 & 4.35 & 25 & 10.42 \\
\hline Total & 309 & 100.00 & 69 & 100.00 & 240 & 100.00 \\
\hline
\end{tabular}

SAHF stay-at-home father, $S A H M$ stay-at-home mother

\section{Anti-spanking}

There were three subthemes under the anti-spanking global theme: One's belief about spanking, one's reflection on others, and one's behavior related to spanking. One's belief about spanking subtheme involved tweets containing stayat-home parents' expressions of anti-spanking beliefs. One's reflection on others subtheme involved tweets exhibiting stay-at-home parents' reflections on others' spanking or related behaviors. One's behavior related to spanking theme involved tweets pertaining to stay-at-home parents' anti-spanking behaviors.

One's belief about spanking Tweets about one's antispanking beliefs made up the largest spanking subtheme. Both fathers and mothers were most likely to tweet about their anti-spanking beliefs compared to tweets that made up other subthemes. These tweets made up approximately onefifth of all fathers' and mothers' tweets. Stay-at-home parents exhibited similar tweets irrespective of gender, with 
Fig. 2 Distribution of spanking subthemes by stay-at-home parent gender. $n=69$ stay-athome father spanking tweets; $n=240$ stay-at-home mother spanking tweets

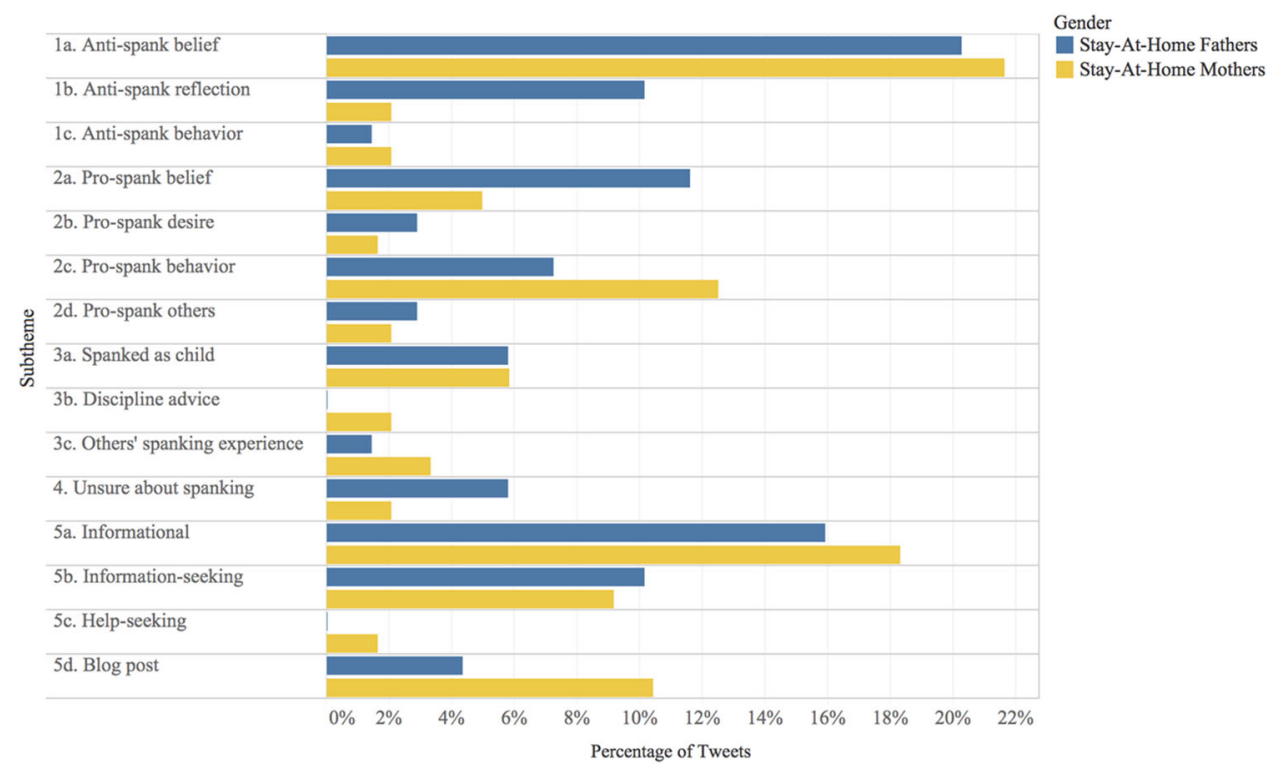

many of them expressing their disapproval of spanking children and criticism against those who employ such a disciplinary method. For example, a mother tweeted her general thoughts about spanking by saying "Spanking a child is still hitting a child so it is child abuse" while another mother tweeted the following in response to an incident involving another parent spanking her son: "So she teaches him that hitting is wrong by spanking him. \#wtf". Compared with mothers, fathers were more likely to invoke the National Football League (NFL) player, Adrian Peterson, who was indicted for child abuse after disciplining his 4year-old son with a switch and bruising his son's body. Fathers expressed their anti-spanking beliefs by condemning the NFL and Peterson's actions (e.g., "I suppose NFL thinks beating children is alright but an adult hitting another adult is not. \#childabuse," "As a stay-at-home father, beating of children was it, man. The Rice video was enough, but Peterson thing was the final nail").

One's reflection on others Although a number of fathers and mothers tweeted their reflections on others' spanking or related behaviors, proportionately more fathers than mothers were likely to tweet about their reflections on others. These tweets were similar in quality to those about anti-spanking beliefs. The major difference lay in the fact that they included a reference to an actual person-another Twitter user, follower, or family member-instead of being a general directive statement (e.g., mother: "Don't ever hit your children"). These reflections included what a parent witnessed other parents doing (e.g. mother: "I once saw a parent spank their six-year-old for hitting another child. So, they will hit their child while saying don't") or heard a family members say (e.g., mother: "What father tells his year-old son he's gonna whoop him if he doesn't stop crying?"). Since Adrian Peterson is an actual person, tweets with reference to him and his actions were double coded under this subtheme.

One's behavior related to spanking Very few stay-athome parents tweeted about their anti-spanking behaviors. The few available tweets mentioned alternatives to spanking or related behaviors, suggesting that a stay-at-home parent is likely to be an anti-spanker. For example, a father tweeted, "I don't spank my kids anymore. I just have them sit in the bathroom with me while I go \#2 now..." Similarly, a mother tweeted, "I think I stopped spanking after I read 'Uncon. Parenting'. It's an inspiration".

\section{Pro-spanking}

There were four subthemes under the pro-spanking global theme: One's belief about spanking, one's desire related to spanking, one's behavior related to spanking, and reference to others. One's belief about spanking subtheme involved tweets containing stay-at-home parents' expressions of prospanking beliefs. One's desires related to spanking subtheme involved tweets containing stay-at-home parents' desires to spank children. One's behavior related to spanking subtheme involved tweets containing stay-athome parents' pro-spanking behaviors. Reference to others subtheme involved tweets containing stay-at-home parents' comments on others' use or practice of spanking.

One's belief about spanking A number of stay-at-home parents posted tweets expressing their pro-spanking beliefs, although fathers were proportionately more likely to post them than mothers. Collectively, these tweets included, but were not limited to, personal stance about spanking (e.g., 
mother: "I believe there's a difference between spanking \& abusing and I see nothing wrong $\mathrm{w} /$ the former as a last resort"); quotes pertaining to spanking (e.g., father: "Spanking a child does not teach him violence. It teaches him not to steal cars -Sinbad"); and definitions of spanking (e.g., mother: "I define spanking as a swat on the child's leg or bottom, hitting is equal to punching w/ a fist $\&$ slapping is equal to hitting on the arm or face").

One's desire related to spanking Although few stay-athome parents posted tweets expressing their desires to spank children, when they did occur, fathers were slightly more likely than mothers to tweet about their desires to spank. These tweets were distinguished from general prospanking beliefs in that they included clear expressions of desire and want. For example, a father tweeted, "Anybody else out there who wants to punch their 2 year old in the face?" Likely responding to an anti-spanking news article, a mother tweeted, “@[news channel anonymized] I hope we as parents can pop our child any day without CPS or the police calling it abuse".

One's behavior related to spanking Pro-spanking behavior was defined broadly to include not only the actual act of spanking a child but also threats of spanking and predictions of spanking behaviors. Mothers were disproportionately more likely to post these tweets than fathers (e.g., mother: "I can't keep the kids down. I'm going to lay the smack down on these rascals"). Some mothers specified the age of their children (e.g., mother: "My 14 years old tried raising her voice at me. I will still whoop that ass \#parenting"). Further, some mothers' tweets suggested spanking other parents' children (e.g., mother: "RT If your child tries to put his hand in my baby's car seat, I will smack his hand. I'm sorry").

Reference to others Few fathers and mothers posted tweets commenting on others' use or practice of spanking. However, when they occurred, these tweets mentioned witnessing another parent spanking a child and praising such behaviors (e.g., father: "RT Just saw a kiddo get smacked over the head by his mother for dabbing. \#parentingwin"); identifying parents who engage in spanking (e.g., mother: “@ [anonymized] @ [anonymized] I think you guys are talking about parents who smack their kidz for any and every little thing"); and being critical of those who were never spanked growing up (e.g., mother: "If some of you all got spanked every now and then growing up maybe you wouldn't be such sensitive little snowflakes as adults").

\section{Experiences related to spanking}

There were three subthemes under the experiences related to spanking global theme: Experienced spanking as a child, discipline advice from others, and spanking experience related to others. Experienced spanking as a child subtheme involved tweets containing stay-at-home parents' recounting experiences of being spanked or experiencing related behavior as a child. Discipline advice from others subtheme involved tweets containing stay-at-home parents' comments about receiving discipline advice from other individuals. Spanking experience related to others subtheme involved tweets containing stay-at-home parents' references to someone else spanking, getting spanked, or any related experience.

Experienced spanking as a child A number of stay-athome parents posted tweets recounting experiences of being spanked or experiencing related behavior as a child, with both fathers and mothers tweeting at equal rates. Both tweeted about being spanked by their own parents. There was more variability in how the tweeter responded to spanking among mothers' tweets than fathers' tweets. For example, mothers tweeted about learning a lesson (e.g., mother: "I was spanked as a kid and learned my lesson real quickly"); deserving the spanking (e.g., mother: "\#wheniwasyourage my parents spanked me. I deserved it every single time. I might still benefit from a good swat once awhile"); and not having a good relationship with their parent as a consequence (e.g., mother: "My mom was a spanker. We don't have a good relationship today. I don't want that for me and my kids").

Discipline advice from others These tweets made up a very small proportion of all the tweets and were posted by mothers only. Most of these tweets involved mothers talking about receiving discipline advice from their own parents (e.g., mother: "As \#child gets older I'm having to politely deflect \#parenting advice from my father. No, I'm not gonna spank my 19 month old ever"). One mother tweeted about getting advice from her child: "Discipline advice from my toddler: 'Mama, don't spank me. Just hug me!' in the sweetest voice ever...Sheesh!".

Spanking experience related to others Similar to tweets about discipline advice, these tweets constituted a small proportion of all the tweets, and the majority were tweeted by mothers. These tweets varied, with mothers recounting their experiences witnessing another parent spanking a child (e.g., "I once witnessed a parent smacking their child") and others tweeting about their direct interactions with other parents (e.g., "Someone offered to spank my kid for me. My response? [link to response post]). Some mothers tweeted about what might generally happen to others as a consequence of a particular behavior (e.g., "Let a parent pop, spank, slap their kids in public for being disobedient and watch people call the cops on that parent"). 


\section{Unsure about spanking}

There were no subthemes under the unsure about spanking global theme because not enough data were available to engage in subcoding. These tweets reflected stay-at-home parents' internal conflicts about whether to use spanking as a disciplinary method. A clear indication of conflict, with evidence for contemplating both spanking and non-spanking as options, needed to be present. Few stay-at-home parents tweeted about this although fathers were proportionately more likely than mothers to tweet about being unsure of employing spanking. These tweets took the form of either a comment (e.g., father: "That moment when you do not know whether to hit or high five your preteenager") or a question asked to their social networks on Twitter (e.g., mother: Hello SAHMs, should you or should you not use corporal punishment like spanking to discipline your kid?").

\section{Facts or information related to spanking}

There were four subthemes under the facts or information related to the spanking global theme: Informational articles, information-seeking, help-seeking, and blog posts. The informational articles subtheme involved tweets referring to general information, news articles, and research findings pertaining to corporal punishment. The information-seeking subtheme involved tweets containing content related to stay-at-home parents actively seeking facts or information about spanking. The help-seeking subtheme involved tweets containing content related to stay-at-home parents actively seeking help and support related to spanking. The blog posts subtheme involved tweets referencing stay-athome parents' or other parents' blogs.

Informational articles For these tweets, we allowed tweets from a wide range of informational sources, including parenting experts, parenting authority sites, news media, universities, and researchers. The tweets made up the second largest set of tweets (i.e., second largest spanking subtheme), followed by anti-spanking belief tweets. Although mothers were more likely than fathers to post informational tweets, the tweets themselves were qualitatively similar across gender. Many of the informational tweets were likely to be retweeted by fathers and mothers. Stay-at-home parents retweeted spanking-related articles from news channels (e.g., CNN) and professional magazines (e.g., Psychology Today) irrespective of gender. A similar trend emerged for retweets of research findings (e.g., "RT An analysis of research on physical punishment of children [link to article]").

Information-seeking A number of stay-at-home parents posted tweets seeking information about spanking, although fathers were slightly more likely than mothers to tweet about seeking information. A majority of these tweets took the form of a question, soliciting answers from individuals in stay-at-home parents' social networks. One father asked, "Is spanking your child an act of discipline or can it be seen as an act of violence? Children see it as parents 'fighting with them.' What do you think?" Similarly, a mother posed this question: "RT Have you ever or do you believe in spanking your kid?".

Help-seeking These help-seeking tweets were distinct from information-seeking tweets in that they clearly demonstrated the despair or helplessness a parent might feel in trying to discipline a child. Words such as help, desperate, and need characterized these tweets. Further, unlike information-seeking tweets, they did not always take the form of a question. Overall, there were very few help-seeking tweets, and all were from mothers (e.g., mother: "My child cries more when his feelings get hurt cuz I said no than when I spank him. Lord help me, my hands are full with him"). A number of help-seeking tweets overlapped with other subthemes, so they were double coded.

Blog posts These tweets were distinct from informational, news, and research article tweets in that they were written primarily by a parent rather than a journalist, parenting expert, or researcher. Although both fathers and mothers tweeted about blog posts, mothers were substantially more likely than fathers to mention such tweets. Stay-at-home parents tweeted about their own blog posts (e.g., father: "Time-outs, spanking, \& other discipline thoughts from a stay-at-home father of 5 kids. [link to blog post]") and retweeted others' blog posts (e.g., mother: "RT Giving up spanking in favor of real world discipline [link to blog post]"). A small group of mothers tweeted content suggestive of video blogs or vlogs.

\section{Discussion}

Our study makes a unique contribution to the literature by expanding parenting and corporal punishment research to Twitter, a virtual setting where parents' attitudes and beliefs can be observed, as well as employing self-presentation theory to interpret findings. The main results demonstrated that stay-at-home parents were most likely to tweet about facts or information related to discipline and spanking compared to tweets that made up other global themes. This was the case across both genders. Personal beliefs about discipline, experiences disciplining a child, anti-spanking stance, and pro-spanking stance were the next most common tweets. 


\section{Informational Tweets and Virtual Norm Setting}

Among global themes, the most common tweets about discipline and spanking were related to facts or information, suggesting that parents who discuss child discipline online may be looking for developmentally appropriate parenting information. This is consistent with prior research demonstrating that parents turn to social media to raise questions about parenting and acquire necessary parenting information (Duggan et al. 2015). Self-presentation theory primarily posits that an individual attempts to control the impression others make of that individual by changing appearances or manners (Goffman 1959). It also argues that those who come in contact with that individual are trying to form opinions and gain information about that individual, suggesting that Twitter users may be aware that those in their social media networks are actively forming opinions about them and thus may want to understand acceptable or normative disciplinary behaviors so as to avoid embarrassment of themselves. This possibly takes the form of asking questions about spanking and obtaining information about what is commonly practiced or recommended amongst their followers.

In general, this informational component of stay-at-home parents' tweets suggests that social media may be a fruitful place for intervening and changing parenting beliefs. We are aware of no examples of Twitter-based parent education interventions that have examined whether Twitter could be used to change parents' beliefs and social norms about the use of corporal punishment. However, experimental research in communication and political science has demonstrated that Twitter-based interventions hold promise for reducing racial harassment and correcting health misinformation (Munger 2016; Vraga and Bode 2017a, 2017b). For instance, Vraga and Bode (2017b) used Twitter to examine to whether corrections from another user or an expert source-the Centers for Disease Control and Prevention (CDC) - were successful in reducing health misinformation about the causes of the spread of the Zika virus and found that a single correction from the CDC on Twitter was sufficient to reduce misinformation among participants. Such research suggests that a similar approach, or even that capitalize on what their followers' endorse in accordance with the self-presentation theory, can be taken to ensure that parents on Twitter are exposed to accurate parental discipline information.

\section{Anti-Spanking Belief Tweets and Changing Norms}

Among spanking subthemes, fathers and mothers most commonly posted spanking tweets that reflected their antispanking beliefs. This seems to be consistent with research demonstrating that there has been a general decline in the use of corporal punishment in the past two decades across all socioeconomic levels, with upper-middle-class mothers reporting the most decline (Fréchette and Romano 2015; Ryan et al. 2016). Similarly, Child Trends (2015) reported that there had been a modest decrease in the proportion of endorsing spanking between 1986 and 2014, especially among women. However, the same report also highlighted that the majority of adults in the U.S. (76\% of men and $65 \%$ of women ages 18-65) agreed that a child sometimes needs to be spanked. Research focusing on low- and middleincome countries has also shown that $43 \%$ of children were spanked or lived in a household where another child was spanked in the last month (Pace et al. 2019). These results point to mixed views regarding parents' endorsement of using corporal punishment. Also, such discrepancies in views likely reflect societal trends in which spanking, although becoming less normative over the years, is still readily used by most parents.

Findings pointing to parents' mixed views on corporal punishment may also suggest that there is a gap between belief and behavior (National Academies of Sciences, Engineering, and Medicine 2016). Parents may increasingly believe that spanking is harmful to children but use spanking anyway, especially in the heat of the moment when levels of parenting stress and negative emotions are high (Hurley 2016) or when they feel the child 'deserves' to be punished (Holden et al. 2014). In support of this, one study with a nationally representative sample of U.S. parents found that $30 \%$ of the parents reported spanking their children even though they did not feel okay about it (Zero to Three 2016). Another study with Canadian parents found that nearly $20 \%$ of them did not endorse corporal punishment but still used mild forms of physical discipline strategies, such as spanking (Fréchette and Romano 2017). This suggests that parent education programs should aim to not only target parenting knowledge, but also parenting motivation and intention that are likely to influence parenting behaviors (National Academies of Sciences, Engineering, and Medicine 2016). Norm changing may require targeting multiple domains of parenting: knowledge, motivation, and behaviors.

Another reason for the discrepant findings may be attributed to Twitter users' selective self-presentation (Goffman 1959). We may have found more anti-spanking tweets by virtue of Twitter users wanting to be viewed positively by their followers (Marwick and Boyd 2011). It may be that stay-at-home parents on Twitter engage in some level of curating a favorable self-image (Marwick and Boyd 2011) by presenting themselves as anti-spankers or advocates against corporal punishment. This could have involved stay-at-home parents censoring tweets or actively managing retweets, which is a pattern found in prior Twitter studies (Uski and Lampinen 2016; Vitak 2012). Given this 
trend that accords with self-presentation theory, there is a need to carefully consider whether Twitter data accurately reflects individuals' views of spanking. Some stay-at-home parents expressing their anti-spanking stances may in reality hold more mixed views or even pro-spanking attitudes and beliefs about the use of spanking than outwardly expressed on Twitter. Although the current research is unable to test this possibility, self-presentation theory and prior Twitter research suggests that those interested in developing interventions on Twitter should take into account that individuals may not always present their true opinions about spanking, and therefore, they should aim to target a wide network of both anti-spankers and pro-spankers on the social media platform. Relatedly, additional research is needed to further elucidate the precise reasons and processes behind stay-at-home mothers' and stay-at-home fathers' selective self-presentation on Twitter. Such a study would likely involve primary data collection (qualitative or quantitative or both) among a sample of Twitter users. Information that has been a standard part of empirical research on parenting (e.g., demographic characteristics of parents and children, parental employment of various disciplinary strategies, and child behavior) could be collected, along with more detailed information on respondents' use of Twitter and other social media. Another approach for future research could involve anonymous online surveys. Because anonymity can encourage self-disclosure and discussion of sensitive topics, researchers could, for example, create anonymous surveys published directly on Twitter (Twitter makes this functionality available in the form of Twitter polls) and ask the users whether their tweets accurately reflected their true opinions. Subsequently, studies may ask why Twitter users engage in behaviors that are concordant or discordant with their true beliefs, as well as how this process plays out for them on their individual Twitter accounts.

\section{Pro-Spanking Tweets Between Gender}

Fathers were more likely than mothers to tweet about beliefs and desires related to spanking, but mothers were more likely than fathers to tweet about spanking behaviors. Although more men than women agree that a child sometimes needs a "good hard spanking" (Child Trends 2015), research on parents' behaviors suggests that mothers engage in discipline more frequently than fathers. In a communitybased study with parents of young children, mothers more frequently engaged in spanking, slapping, hitting, and nonaggressive disciplinary behaviors than did fathers (Kim et al. 2014). Another study found that mothers self-reported slightly higher levels of spanking than did fathers (Lee et al. 2012). These gender differences may be explained by the fact that mothers spend more time with their young children than do fathers (Day and Lamb 2004). This would not necessarily hold true for fathers, who are the primary caregivers of their children. Related to the current study, it is possible that fathers may be warier than mothers of the stigma attached to publicly reporting spanking a child and the implications for tweeting such content (e.g., involvement by Child Protective Services or label as a child abuser). This also suggests that fathers may be more prone than mothers to engage in selective self-presentation to curate and preserve a positive self-image online. Further research is needed to disentangle reasons behind why fathers might be tweeting more pro-spanking beliefs and desires than mothers and mothers tweeting more pro-spanking behaviors than fathers. Studies involving survey items, as well as qualitative interviews, with stay-at-home fathers and mothers who actively use Twitter are needed.

\section{Traditional Gender and Social Norms}

Some stay-at-home parents' tweets seemed to reflect what may be considered traditional gender and social norms. As a case in point, mothers were more likely than fathers to tweet about parenting advice from other people, spanking experiences related to others, and blog posts. These patterns are consistent with research demonstrating that mothers are more likely than fathers to turn to non-spouse family members and friends for parenting advice (Pew Research Center 2015), as well as have their own blogs and write blog posts (Friedman 2016). Prior research suggests that men typically rely on women for parenting information (Dayton et al. 2016). Moreover, our study's findings indicate that fathers were more likely than mothers to be unsure about using spanking as a disciplinary method. It is plausible that, compared with mothers, fathers lack parenting knowledge pertaining to spanking, but more research is needed to understand why they may be feeling uncertain about spanking. Traditional gender and social norms may also be seen on Twitter due to tenets of self-presentation. That is, mothers and fathers online may conform and subscribe to traditional norms in order to curate a self-image that appeals and resonates with their followers, who may easily "unfollow" them for differences in opinions, interests, and values. For those actively creating and maintaining an active online presence, acceptance by their followers may be important to continue their influence on social media. This may result in tweeting out posts that reflect traditional gender and social norms.

\section{Limitations and Future Research}

There are some key limitations to the current study. First, there are clearly social selection issues at play in our data collection, as we limited our sample to only stay-at-home 
parents who had a Twitter account and directly posted tweets about child discipline issues. Stay-at-home parentsespecially stay-at-home fathers-are also likely to be somewhat different from non-stay-at-home parents, as demonstrated by prior research (Fischer and Anderson 2012; Solomon 2014). Second, snowball sampling can be prone to bias because of the correlations between individuals. That is, Twitter users in the subsequent round of data collection are not independent of Twitter users in the first round of data collection, which could ultimately yield biased or inconsistent results. For these reasons, results of the study should be interpreted with caution.

Third, middle- to upper-middle-income individuals are more likely to use Twitter than low-income individuals (Greenwood et al. 2016), limiting our knowledge of how low-income parents may express their parenting beliefs on social media. Our results cannot be generalized to the broader group of stay-at-home parents who do not participate in this form of social media. Fourth, we are unable to describe the demographic characteristics of our sample, given the limited sociodemographic information that could be obtained from Twitter. Finally, our study procedure resulted in a relatively small sample of tweets from stay-athome parents. This may suggest that stay-at-home parents on Twitter do not tweet about discipline and spanking. This could be an artifact of Twitter's 280-character limitation, which does not allow space for in-depth conversations on spanking.

More research on parents' beliefs about corporal punishment is warranted. Social media provides an important avenue in which to examine how parents discuss parenting, seek parenting information, form supportive networks, and express parenting beliefs. Failure to utilize this data source may be a missed opportunity because social media-especially a predominantly open and public platform like Twitter-creates an environment where parenting attitudes and behaviors can be observed. Our study sheds light on the ways in which stay-at-home parents publicly talk about discipline and spanking. The existence of a community of parents discussing disciplinary issues on Twitter suggests that this form of social media may be amenable to normsetting interventions that attempt to make use of the network of Twitter users. It is worth considering emerging forms of intervention, such as No Hit Zones in hospitals (Frazier et al. 2014), which are designed to influence norms around parenting and suggest that spanking is an unacceptable way to discipline children. It is possible that professionals, including researchers and clinicians, can help extend such norm-influencing interventions to social media.

This study also raises important questions about the role of professionals with access to social media in addressing truly problematic inclinations, such as the parent who suggested beating a 2-year-old child. Professionals play a key role in influencing parents' attitudes toward corporal punishment (Taylor et al. 2013). Together, clinicians, educators, and researchers have the responsibility to prevent and address corporal punishment and violence against children. This also applies to when they come across threats of such acts in tweets or other social media posts. Professionals can educate the social media user of the consequences of corporal punishment and violence on children's health and development, as well as provide alternative strategies for effective discipline. A reply to a tweet or post with a corrective or an educational comment may serve as a start to confronting and changing the online user's attitude. This approach is consistent with a brief online program using education to reduce adults' positive attitudes towards corporal punishment (Holden et al. 2014).

In sum, our study used Twitter-an innovative source of parenting data and social media platform where parents were less likely to be concerned with social desirability and thus could share their thoughts and opinions - to examine stay-at-home parents' publicly available spanking tweets. Our research also captured parenting information directly from fathers. Researchers have noted the absence of fathers in social science research and the challenges of engaging fathers in studies (Cabrera et al. 2018; Pretorius et al. 2019). Our study methodology gave us access to fathers, allowing us to better understand how a group of traditionally understudied fathers - men who are primary caregiversthink about sensitive parenting topics such as corporal punishment.

\section{Data Availability}

The qualitative codebook used for the current study is available at Open Science Framework (https://osf.io/ $8 y 2 \mathrm{mf}$ ). Data could not be made available due to ethical constraints concerning identifiable information, including Twitter handles.

Acknowledgements This manuscript is based upon work supported by the University of Michigan, Rackham Graduate School [Application $\# 185,2017]$. The sponsor was not directly involved in any aspect of the research.

Funding J.Y.L. and T.A. received funding from the University of Michigan Rackham Graduate School as part of the Rackham Interdisciplinary Workshop that supported this research.

Author Contributions J.Y.L. designed the study, collected data, cleaned the data, conducted the main analyses, and wrote the manuscript. A.C.G.K. provided supervision of the main analyses, wrote the manuscript, and edited the manuscript. S.J.L. provided guidance with framing the study using theory, wrote parts of the manuscript, and edited the manuscript. T.A. assisted with cleaning the data. A.L. also assisted with cleaning the data, as well as coding and analyzing the data. P.D.K. provided supervision of the main analyses and edited and reviewed the manuscript. 


\section{Compliance with Ethical Standards}

Conflict of Interest All authors declare that they have no conflict of interest.

Ethical Approval The current study was reviewed by the University of Michigan Health Sciences and Behavioral Sciences Institutional Review Board (IRB) and was considered secondary data analysis (HUM00143436), given the use of publicly available data. As such, the study was considered to be exempt from IRB oversight.

Informed Consent Given that data were publicly available, informed consent was not directly obtained from participants included in this study. However, consent to collection and use of data was obtained from all individual participants by Twitter per their privacy policy (https://twitter.com/en/privacy).

Publisher's note Springer Nature remains neutral with regard to jurisdictional claims in published maps and institutional affiliations.

\section{References}

Ammari, T., \& Schoenebeck, S. (2015). Understanding and supporting fathers and fatherhood on social media sites. In Proceedings of the 33rd Annual ACM Conference on Human Factors in Computing Systems, 1905-1914. Seoul, Republic of Korea. https:// doi.org/10.1145/2702123.2702205.

Ammari, T., Schoenebeck, S. Y., \& Romero, D. (2018). Pseudonymous parents: comparing parenting roles and identities on the mommit and daddit subreddits. In Proceedings of the ACM Conference on Human Factors in Computing Systems. Montreal QC, Canada. https://doi.org/10.1145/3173574.3174063.

Bartholomew, M. K., Schoppe-Sullivan, S. J., Glassman, M., Kamp Dush, C. M., \& Sullivan, J. M. (2012). New parents' Facebook use at the transition to parenthood. Family Relations, 61(3), 455-469.

Bazarova, N. N., \& Choi, Y. H. (2014). Self-disclosure in social media: extending the functional approach to disclosure motivations and characteristics on social network sites. Journal of Communication, 64(4), 635-657. https://doi.org/10.1111/jcom. 12106.

Brems, C., Temmerman, M., Graham, T., \& Broersma, M. (2017). Personal branding on Twitter. How employed and freelance journalists stage themselves on social media. Digital Journalism, 5(4), 443-459. https://doi.org/10.1080/21670811.2016.1176534.

Brown, A. S., Holden, G. W., \& Ashraf, R. (2016). Spank, slap, or hit? How labels alter perceptions of child discipline. Psychology of Violence, 8(1), 1-9. https://doi.org/10.1037/vio0000080.

Cabrera, N. J., Volling, B. L., \& Barr, R. (2018). Fathers are parents, too! Widening the lens on parenting for children's development. Child Development Perspectives, 12(3), 152-157. https://doi.org/ 10.1111/cdep.12275.

Cha, M., Hamed, H., Fabricio, B., \& Krishna, P. G. (2010). Measuring user influence in Twitter: the million follower fallacy. In Proceedings of the Fourth International AAAI Conference on Weblogs and Social Media (ICWSM 2010). Washington, DC: AAAI Press.

Child Trends. (2015). Attitudes toward spanking: indicators of child and youth well-being. https://www.childtrends.org/wp-content/ uploads/2015/11/51_Attitudes_Toward_Spanking.pdf.

Day, R. D., \& Lamb, M. E. (2004). Conceptualizing and measuring father involvement. Mahwah, NJ: Erlbaum.
Dayton, C. J., Buczkowski, R., Muzik, M., Goletz, J., Hicks, L., Walsh, T. B., \& Bocknek, E. L. (2016). Expectant fathers' beliefs and expectations about fathering as they prepare to parent a new infant. Social Work Research, 40(4), 225-236. https://doi.org/10. 1093/swr/svw017.

Donnelly, M., \& Straus, M. (2005). Corporal punishment of children in theoretical perspective. New Haven; London: Yale University Press.

Duggan, M., Lenhart, A., Lampe, C., \& Ellison, N. B. (2015). Parents and social media. Pew Research Center, Internet \& Technology. http://www.pewinternet.org/2015/07/16/parents-and-socialmedia/.

Fraga, J. (2017). As they dig deeper into parenting, fathers seek community, support. NPR. https://www.npr.org/sections/healthshots/2017/02/21/515414558/as-they-dig-deeper-into-parentingfathers-seek-community-support.

Fréchette, S., \& Romano, E. (2015). Change in corporal punishment over time in a representative sample of Canadian parents. Journal of Family Psychology, 29(4), 507-517. https://doi.org/10.1037/fa $\mathrm{m} 0000104$.

Fréchette, S., \& Romano, E. (2017). How do parents label their physical disciplinary practices? A focus on the definition of corporal punishment. Child Abuse \& Neglect, 71, 92-103. https:// doi.org/10.1016/j.chiabu.2017.02.003.

Fischer, J., \& Anderson, V. N. (2012). Gender role attitudes and characteristics of stay-at-home and employed fathers. Psychology of Men \& Masculinity, 13(1), 16-31. https://doi.org/10.1037/a 0024359.

Frazier, E. R., Liu, G. C., \& Dauk, K. L. (2014). Creating a safe place for pediatric care: a no hit zone. Hospital Pediatrics, 4(4), 247-250. https://doi.org/10.1542/hpeds.2013-0106.

Friedman, M. (2016). Daddyblogs know best: histories of fatherhood in the cyber age. In E. Podnieks (Ed.), Pops in pop culture: fatherhood, masculinity, and the new man (pp. 87-103). New York, NY: Palgrave Macmillan.

Gershoff, E. T., \& Grogan-Kaylor, A. (2016). Spanking and child outcomes: old controversies and new meta-analyses. Journal of Family Psychology, 30(4), 453-469. https://doi.org/10.1037/fa m0000191.

Goffman, E. (1959). The presentation of self in everyday life. New York, NY: Doubleday.

Greenwood, S., Perrin, A., \& Duggan, M. (2016). Social media update 2016. Pew Research Center, Internet \& Technology. http://www. pewinternet.org/2016/11/11/social-media-update-2016/.

Holden, G. W., Brown, A. S., Baldwin, A. S., \& Caderao, K. C. (2014). Research findings can change attitudes about corporal punishment. Child Abuse \& Neglect, 38(5), 902-908. https://doi. org/10.1016/j.chiabu.2013.10.013.

Holden, G. W., Miller, P. C., \& Harris, S. D. (1999). The instrumental side of corporal punishment: parents' reported practices and outcome expectancies. Journal of Marriage and Family, 61(4), 908-919.

Holden, G. W., Williamson, P. A., \& Holland, G. W. O. (2014). Eavesdropping on the family: a pilot investigation of corporal punishment in the home. Journal of Family Psychology, 28(3), 401-406. https://doi.org/10.1037/a0036370.

Hudson, D. B., Elek, S. M., \& Fleck, C. M. (2001). First-time mothers' and fathers' transition to parenthood: infant care self-efficacy, parenting, and infant sex. Issues in Comprehensive Pediatric Nursing, 24(1), 31-43.

Hurley, K. (2016). Many still spank their kids in the heat of the moment: Here's how to parent more effectively. The Washington Post. https://www.washingtonpost.com/news/parenting/wp/2016/ 10/12/remaining-calm-when-dealing-with-tantrums-is-a-skillheres-how-to-get-it/?utm_term $=.5 \mathrm{af} 81 \mathrm{f} 0 \mathrm{a} 4 \mathrm{fbd}$. 
Jeynes, W. H. (2016). Meta-analysis on the roles of fathers in parenting: are they unique? Marriage \& Family Review, 52(7), 665-688. https://doi.org/10.1080/01494929.2016.1157121.

Kim, J., Lee, S. J., Taylor, C. A., \& Guterman, N. B. (2014). Dyadic profiles of parental disciplinary behavior and links with parenting context. Child Maltreatment, 19(2), 79-91. https://doi.org/10. 1177/1077559514532009.

Lansford, J. E., Alampay, L. P., Al-Hassan, S., Bacchini, D., Bombi, A. S., Bornstein, M. C., \& Zelli, A. (2010). Corporal punishment of children in nine countries as a function of child gender and parent gender. International Journal of Pediatrics, 2010, 1-12. https://doi.org/10.1155/2010/672780.

Lee, J. Y., \& Lee, S. J. (2018). Caring is masculine: stay-at-home fathers and masculine identity. Psychology of Men \& Masculinity, 19(1), 47-58. https://doi.org/10.1037/men0000079.

Lee, S. J., Lansford, J. E., Pettit, G. S., Bates, J. E., \& Dodge, K. A. (2012). Parental agreement of reporting parent to child aggression using the conflict tactics scales. Child Abuse \& Neglect, 36(6), 510-518. https://doi.org/10.1016/j.chiabu. 2012.04.005.

Lyles, C. R., López, A., Pasick, R., \& Sarkar, U. (2013). "5 min of uncomfyness is better than dealing with cancer 4 a lifetime": an exploratory qualitative analysis of cervical and breast cancer screening dialogue on Twitter. Journal of Cancer Education, 28 (1), 127-133. https://doi.org/10.1007/s13187-012-0432-2.

Marwick, A. E., \& Boyd, D. (2011). I tweet honestly, I tweet passionately: Twitter users, context collapse, and the imagined audience. New Media \& Society, 13(1), 114-133. https://doi.org/ $10.1177 / 1461444810365313$.

McHugh, M. L. (2012). Interrater reliability: the kappa statistic. Biochemia Medica, 22(3), 276-282.

Metaxas, P. T., \& TwitterTrails Research Team. (2017). Retweets indicate agreement, endorsement, trust: a meta-analysis of published Twitter research. https://arxiv.org/pdf/1411.3555.pdf.

Milford, C., Kriel, Y., Njau, I., Nkole, T., Gichangi, P., \& Cordero, J. P., the UPTAKE Project Team. (2017). Teamwork in qualitative research: descriptions of a multicountry team approach. InternationalJournal of Qualitative Methods, 16(1), 1-10. https://doi. org/10.1177/1609406917727189.

Munger, K. (2016). Tweetment effects on the tweeted: experimentally reducing racist harassment. Political Behavior, 39(3), 629-649. https://doi.org/10.1007/s11109-016-9373-5.

National Academies of Sciences, Engineering, and Medicine. (2016). Parenting knowle dge, attitudes, and practices. In H. Breiner, M. Ford, \& V. L. Gadsden (Eds) Parenting matters: supporting parents of children ages 0-8 (vol. 2). Washington, DC: National Academies Press. https://www.ncbi.nlm.nih.gov/books/ NBK402020/.

Pace, G. T., Lee, S. J., \& Grogan-Kaylor, A. (2019). Spanking and young children's socioemotional development in low- and middle-income countries. Child Abuse \& Neglect, 88, 84-95. https://doi.org/10.1016/j.chiabu.2018.11.003.

Pelchant, D., Lefebvre, H., \& Perreault, M. (2003). Differences and similarities between mothers' and fathers' experiences of parenting a child with a disability. Journal of Child Health Care, 7(4), 231-247. https://doi.org/10.1177/13674935030074001.

Pew Research Center. (2015). Parenting in America: Outlook, worries, aspirations are strongly linked to financial situation. https://www. pewresearch.org/wp-content/uploads/sites/3/2015/12/2015-1217_parenting-in-america_FINAL.pdf.

Pretorius, K., Johnson, K. E., \& Rew, L. (2019). An integrative review: understanding parental use of social media to influence infant and child health. Maternal Child Health Journal, 23(10), 1360-1370. https://doi.org/10.1007/s10995-019-02781-w.

Ryan, R., Kalil, A., Ziol-Guest, K. M., \& Padilla, C. (2016). Socioeconomic gaps in parents' discipline strategies from 1988 to 2011. Pediatrics, 138(6), 1-8. https://doi.org/10.1542/peds.2016-0720.

Schoenebeck, S. Y. (2013). The secret life of online moms: anonymity and disinhibition on YouBeMom.com. In Proceedings of the Seventh International AAAAI Conference on Weblogs and Social Media, Cambridge, Massachusetts. 555-562.

Solomon, C. R. (2014). "I feel like a rock star:" fatherhood for stay-athome fathers. Fathering, 12(1), 57-70. https://doi.org/10.3149/ fth.1201.52.

Stahlschmidt, M. J., Threlfall, J., Seay, K. D., Lewis, E. M., \& Kohl, P. L. (2013). Recruiting fathers to parenting programs: advice from dads and fatherhood program providers. Children and Youth Services Review, 35(10), 1734-1741. https://doi.org/10.1016/j. childyouth.2013.07.004.

Taylor, C. A., Al-Hiyari, R., Lee, S. J., Priebe, A., Guerrero, L. W., \& Bales, A. (2016). Beliefs and ideologies linked with approval of corporal punishment: a content analysis of online comments. Health Education Research, 31(4), 563-575. https://doi.org/10. 1093/her/cyw029.

Taylor, C. A., Moeller, W., Hamvas, L., \& Rice, J. C. (2013). Parents' professional sources of advice regarding child discipline and their use of corporal punishment. Clinical Pediatrics, 52(2), 147-155. https://doi.org/10.1177/0009922812465944.

Tsukayama, H. (2017). Twitter is officially doubling the character limit to 280. The Washington Post. https://www.washingtonpost. com/news/the-switch/wp/2017/11/07/twitter-is-officiallydoubling-the-character-limit-to-280/?utm_term $=.64115 \mathrm{bf} 32748$.

Twitter, Inc. (n.d.a). Follow, search, and get users. https://developer. twitter.com/en/docs/accounts-and-users/follow-search-get-users/a pi-reference/get-followers-list.

Twitter, Inc. (n.d.b). Get tweet timelines. https://developer.twitter.com/ en/docs/tweets/timelines/api-reference/get-statuses-user_timeline. html.

United Nations Children's Fund. (2014). Hidden in plain sight: A statistical analysis of violence against children. https://files. unicef.org/publications/files/Hidden_in_plain_sight_statistical_a nalysis_EN_3_Sept_2014.pdf.

Uski, S., \& Lampinen, A. (2016). Social norms and self-presentation on social network sites: profile work in action. New Media \& Society, 18(3), 447-464. https://doi.org/10.1177/1461444814543164.

van der Nagel, E. (2018). Alts and automediality: compartmentalising the self through multiple social media profiles. M/C: A Journal of Media and Culture, 21(2), 1-4.

Vitak, J. (2012). The impact of context collapse and privacy on social network site disclosures. Journal of Broadcasting \& Electronic Media, 56(4), 451-470.

Vraga, E. K., \& Bode, L. (2017a). I do not believe you: how providing a source corrects health misperceptions across social media platforms. Information, Communication \& Society, 21(10), 1-17. https://doi.org/10.1080/1369118X.2017.1313883.

Vraga, E. K., \& Bode, L. (2017b). Using expert sources to correct health misinformation in social media. Science Communication, 39(5), 621-645. https://doi.org/10.1177/1075547017731776.

Wissow, L. S. (2001). Ethnicity, income, and parenting contexts of physical punishment in a national sample of families with young children. Child Maltreatment, 6(2), 118-129.

Zero to Three. (2016). National parent survey overview and key insights. https://www.zerotothree.org/resources/1424-national-pa rent-survey-overview-and-key-insights\#downloads. 